\title{
ADVANCED BINARY GEOTHERMAL POWER PLANTS LIMITS OF PERFORMANCE
}

\author{
C. J. Bliem \\ G. L. Mines
}

Published January 1991

EG\&G Idaho, Inc.

Idaho Fal1s, Idaho 83415

Prepared for the

U.S. Department of Energy

Idaho Operations office

Under DOE Contract No. DE-ACO7-76ID01570

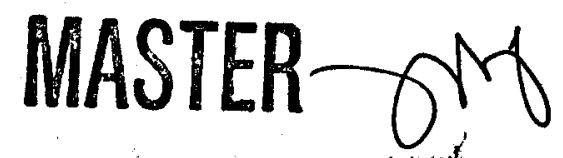




\section{DISCLAIMER}

This report was prepared as an account of work sponsored by an agency of the United States Government. Neither the United States Government nor any agency Thereof, nor any of their employees, makes any warranty, express or implied, or assumes any legal liability or responsibility for the accuracy, completeness, or usefulness of any information, apparatus, product, or process disclosed, or represents that its use would not infringe privately owned rights. Reference herein to any specific commercial product, process, or service by trade name, trademark, manufacturer, or otherwise does not necessarily constitute or imply its endorsement, recommendation, or favoring by the United States Government or any agency thereof. The views and opinions of authors expressed herein do not necessarily state or reflect those of the United States Government or any agency thereof. 


\section{DISCLAIMER}

Portions of this document may be illegible in electronic image products. Images are produced from the best available original document. 


\section{ACKNOWLEDGEMENTS}

The work in this report was undertaken to answer a question put to one of the authors by Raymond LaSala of the Department of Energy's Geothermal Division. Ray asked how closely an actual binary geothermal system could approach the thermodynamic maximum conversion of the thermal energy in the geofluid to work, feeling that $75 \%$ might leave significant room for improvement. One of the authors (CJB) could not answer the question related to the magnitude of the irreversibilities associated with the necessary transfer of heat (pinch points or log mean temperature differences) and conversion to work in rotating machinery (isentropic efficiencies). This report is the result of our thinking on this subject. Thanks, Ray.

The report has been reviewed by several people in the industrial sector for their perspective. We acknowledge the effort of Richard Campbell of the Ben Holt Company, Michael Forsha of Barber Nichols Engineering, and Joel Rosenblatt and Stanley Saulson of Polythermal Technologies Corporation for their review of the initial report. In addition, we thank the people at Exergy Inc. who generated the numbers for comparable cases for their System 12 to the performance of the other systems.

Most of all the authors acknowledge Dr. Alexander Kalina of Exergy Inc. who gave us the "Rule-of-Thumb" that economic optimization occurred at second 1aw efficiencies in the neighborhood of 70 to $75 \%$ for systems of the type being considered here.

We are greatful for all of the assistance received from the Department of Energy and the industrial sector. The conclusions, however, are those of the authors alone. 



\section{ABSTRACT}

The Heat Cycle Research Program is investigating potential improvements to power cycles utilizing moderate temperature geothermal resources to produce electrical power. Investigations have specifically examined Rankine cycle binary power systems. Binary Rankine cycles are more efficient than the flash steam cycles at moderate resource temperatures, achieving a higher net brine effectiveness. At resource conditions similar to those at the Heber binary plant, it has been shown that mixtures of saturated hydrocarbons (alkanes) or halogenated hydrocarbons operating in a supercritical Rankine cycle gave improved performance over Rankine cycles with the pure working fluids executing single or dual boiling cycles or supercritical cycles.

Recently, in addition to the supercritical Rankine Cycle, other types of cycles have been proposed for binary geothermal service. This report explores the feasible limits on efficiency of a plant given practical limits on equipment performance and discusses the methods used in these advanced concept plants to achieve the maximum possible efficiency. (Here feasible is intended to mean reasonably achievable and not cost-effective. No direct economic analysis has been made because of the sensitivity of economic results to site specific input. The intent here is to take a generic look at systems which will probably be cost effective when used in specific applications. The results are expected to be close to the economically feasible points.) The limit of performance of three advanced plants were considered in this report. The performance predictions were taken from the developers of each concept. The advanced plants considered appear to be approaching the feasible limit of performance. Ultimately, the plant designer must weigh the advantages and disadvantages of the different cycles to find the best plant for a given service.

In addition to the results described in the previous paragraph, this report presents a standard of comparison of the work which has been done in the Heat Cycle Research Program and in the industrial sector by Exergy, Inc. and Polythermal Technologies. The report can be considered a "Report Card" of sorts indicating how far we have come and how much further it is feasible to go in performance of these energy conversion systems. 


\section{CONTENTS}

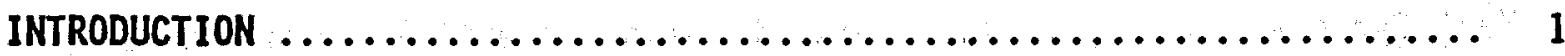

CYClE PERFORMANCE LIMITATION $\ldots \ldots \ldots \ldots \ldots \ldots \ldots \ldots \ldots \ldots \ldots \ldots \ldots \ldots \ldots$

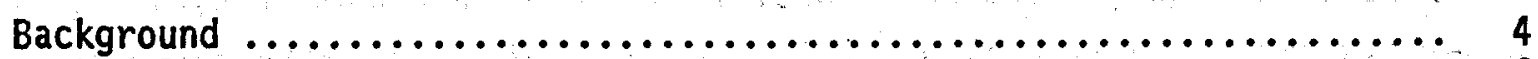

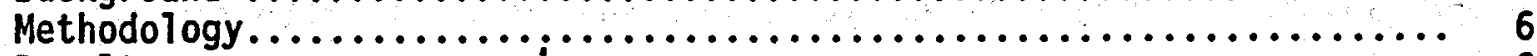

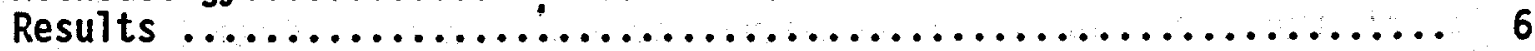

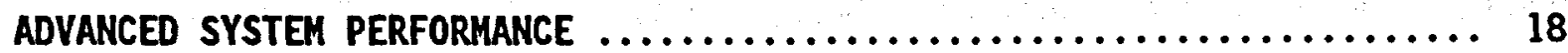

Systems With Outlet Temperature Constraints.................... 18

Systems Without Outlet Temperature Constraints ................ 26

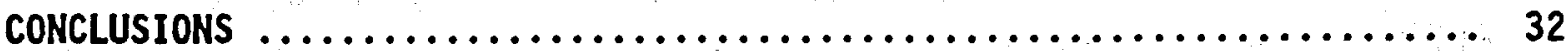

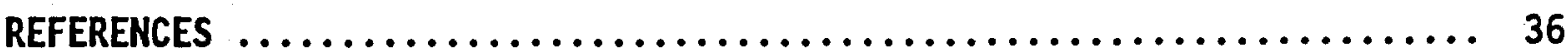

\section{FIGURES}

Figure 1. "Unobtainium" cycle with unconstrained

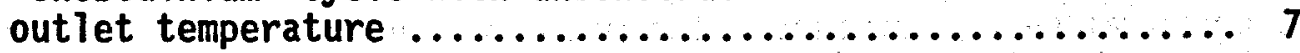

Figure 2. Efficiency of "unobtainium" cycle with unconstrained outlet temperature ................... 9

Figure 3. "Unobtainium" cycle with constrained outlet temperature

Figure 4. Efficiency of "unobtainium" cycle with constrained outlet temperature $\ldots \ldots \ldots \ldots \ldots \ldots \ldots \ldots \ldots 13$

Figure 5. Recuperated rankine cycle $\ldots \ldots \ldots \ldots \ldots \ldots \ldots \ldots \ldots \ldots$

Figure 6. Recuperated "unobtainium" cycle with Constrained Outlet Temperature .................... 15

Figure 7. Efficiency of recuperated "unobtainium" cycle with constrained outlet temperature $\ldots \ldots \ldots \ldots \ldots \ldots 17$

Figure 8. Temperature-enthalpy diagram for supercritical rankine cycle $\ldots \ldots \ldots \ldots \ldots \ldots \ldots \ldots \ldots \ldots 19$

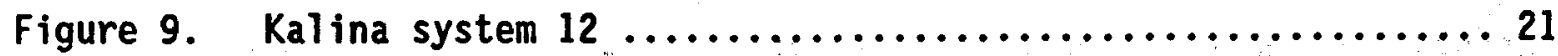

Figure 10. Temperature-enthalpy diagram for kalina system 12

Figure 11. Comparison between kal ina system 12 and a supercritical rankine cycle 
Figure 12. Comparison between two cycles $\ldots \ldots \ldots \ldots \ldots \ldots \ldots \ldots \ldots . \ldots 26$

Figure 13. The trilateral cycle $\ldots \ldots \ldots \ldots \ldots \ldots \ldots \ldots \ldots \ldots \ldots, 28$

Figure 14. Supercritical rankine with expansion

"through-the-vapor-dome"

Figure 15. Temperature-enthalpy diagram comparing cycles with no minimum outlet temperature 1 imits $\ldots \ldots \ldots \ldots \ldots . . .30$

Figure 16. Comparison between cycles with no minimum temperature 1 imit $\ldots \ldots \ldots \ldots \ldots \ldots \ldots \ldots \ldots . \ldots . \ldots . \ldots$

Figure 17. Results for advanced systems $\ldots \ldots \ldots \ldots \ldots \ldots \ldots \ldots \ldots . \ldots . \ldots$

\section{TABLES}

Table 1. Silica deposition limits $\ldots \ldots \ldots \ldots \ldots \ldots \ldots \ldots \ldots \ldots \ldots \ldots$ 


\section{ADVANCED BINARY GEOTHERMAL POWER PLANTS \\ LIMITS OF PERFORMANCE}

\section{IKTRODUCTION}

The Heat Cycle Research Program is currently investigating potential improvements to power cycles utilizing moderate-temperature geothermal resources to produce electrical power. The technology being considered either improves the performance of the power cycle thus reducing the cost of electricity, or it provides a means of utilizing a resource which might otherwise not be used because of institutional or technical barriers. Although geothermal energy is provided by nature, it is generally expensive to produce, and compared to fossil fuel, is a low grade energy source. Because of the low quality and high cost of the energy, optimized systems for the generation of electrical power should utilize as much of the energy contained in a unit mass of the fluid as possible. This optimization was confirmed with both a "value analyses" study and a "market penetration" study which examined the impact of performance improvements on the cost of electricity and on the future utilization of geothermal produced electrical power if these improvements could be realized ${ }^{1,2}$. The net brine effectiveness, or the net electrical energy produced by the plant per unit mass of geofluid, has been used by this program as a primary indicator of the improvements in the cycle performance.

In previous work in the Heat Cycle Research Program, the net plant output included the parasitic power resulting from heat rejection, but did not include the parasitic power required to produce and inject the geofluid. The rationale for this was that the geofluid power requirements were site specific and no generic approximation was valid. Today, with many different types of heat rejection systems, the same could be said for the heat rejection parasitic. There are many different types of heat rejection used in different environments in geothermal applications today from total dry cooling to wet cooling with conventional cooling towers. It is believed that in order to make the results more meaningful, the heat rejection parasitic should be considered as a separate issue in the same manner as is used for the geofluid production parasitic. Therefore, in this report, the net plant power does not include the heat rejection parasitic. In addition, the results 
in this report are given in terms of a second law efficiency instead of a geofluid effectiveness. The geofluid effectiveness can be obtained by multiplying the second law efficiency by the available energy in the geofluid (per unit mass of geofluid). The use of the efficiency gives a parameter which is relatively independent of resource temperature, while the maximum geofluid effectiveness (the available energy in the geofluid) is a strong function of resource temperature.

- The Heat Cycle Research Program investigations have specifically examined binary power cycles because for the moderate temperature resources of interest, the binary cycles are more efficient than the flash steam cycles, achieving a higher net brine effectiveness. In these investigations of the binary power cycle, advanced concepts such as supercritical heating, integral countercurrent condensation, appropriate choice of working fluid, and metastable turbine expansions were explored. At resource conditions similar to those at the Heber binary plant, Demuth ${ }^{3.4}$ and Demuth and Kochan ${ }^{5}$ found that mixtures of saturated hydrocarbons (alkanes) with these advanced concepts gave a $29 \%$ performance improvement over the Heber plant: Bliem ${ }^{6}$ in subsequent studies showed that the same results were true if halocarbon mixtures (Freons) were used.

With the projected improvements in performance from the concepts identified in these analytical studies, the program has initiated field investigations to further examine the potential performance gains with these concepts ${ }^{7,8}$. The field investigations of the concepts are being conducted at the Heat Cycle Research Facility currently located at East Mesa in California's Imperial Valley. These field studies examine the validity of the predicted performance improvements through the verification of the assumptions used in the predictions, and the adequacy of the "state-of-the-technology" design methods, including fluid transport properties. Methods to insure that assumed conditions such as integral, countercurrent phase change have been achieved.

Recently, a number of new concepts for power cycles for geothermal use have been introduced and published performance data for these systems is available. For this paper, the operating conditions for the supercritical Rankine cycle have been adjusted for direct comparison with the other systems. In January of 1989, Exergy Inc. Introduced the Kalina System 12 for geothermal use ${ }^{9}$. Polythermal Technologies Corporation is considering their Low-Temperature Engine System for power production 
from a flashing well ${ }^{10}$. This system employs a heat-driven heat pump and two separate heat engine cycles. One engine's heat input is from the heat rejected by the other engine and this engine rejects heat to the heat pump at a temperature lower than atmospheric which is pumped to atmospheric by the heat pump. In the United Kingdom, the Trilateral Wet Expansion System is being proposed for a binary application with a hot-dry rock resource ${ }^{11}$. These new concepts rely on similar considerations to those studied in the Heat Cycle Research Facility (HCRF). One of the primary prerequisites for the achievement of the predicted performance of each of these systems which utilize mixtures of hydrocarbons as working fluids is that phase changes (botling and condensation) be carried out close to equilibrium with the phases mixed. This has been studied in the HCRF in detail for the condensation process. In the HCRF investigations, the use of supercritical vaporization allows the generation of vapor without the problems associated with boiling a two-component mixture.

For all such cycles, there is a cycle performance limit for a given resource and sink temperatures, and practical assumptions relative to rotating equipment efficiencies and heat exchanger approach temperature differences or $\log$ mean temperature differences (LMTD's). This report examines this performance 1 imit and reviews the performance of some of the advanced systems.

The Heat Cycle Research program is being conducted by the Idaho National Engineering Laboratory. The work is supported by the U.S. Department of Energy, Assistant Secretary for Conservation and Renewable Energy, under DOE contract No. DE-AC07-76ID01570. Mr. Raymond LaSala of the Geothermal Division is the program manager and $\mathrm{Mr} . \mathrm{K}$. J. Taylor directs the program through the Idaho Operations office. 


\section{CYCLE PERFORMANCE LIMITATION}

Background

A second-1aw-of-thermodynamics analysis is useful in determining the limitations of performance of power generation systems. Briefly, the second law allows for the definition of available energy, defined by Obert ${ }^{12}$ :

\footnotetext{
"Available energy is that portion of energy which could be converted into work by ldeal processes which reduce the system to dead state--a state in equilibrium with the earth and its atmosphere."
}

If a system is at a different pressure from the atmosphere, work can be obtained by expansion to atmospheric pressure. If a system is at a different temperature than the surroundings, work may be obtained by transferring heat to a work producing cycle (heat engine). If chemical reactions are possible, for example, if the substance is a hydrocarbon, a reaction which oxidizes the hydrogen to water and the carbon to carbon dioxide or carbonate has the potential to produce work. (In this report, chemical reaction will not be considered.) Available energy is essentially the same as availability, exergy and essergy.

The available energy, $A$, of a stream in steady flow is:

$$
A=m\left[\left(h-h_{0}\right)-T_{0}\left(s-s_{0}\right)\right]
$$

where $m$ is the mass flow rate; $h$, enthalpy; $T$, absolute temperature; and $s$, entropy. The subscript o represents the value at the pressure and temperature of the environment, the dead state.

The irreversibility of a process or physical component, $I$, is the sum of all of the increases and decreases in available energy occurring and can be shown to be equal to:

$$
I=-T_{0} \Sigma m_{n} D s_{n}
$$

where $T_{0}$ is the absolute ambient temperature; $m_{n}$, the mass flow rate of the $n$th stream; and $D s_{n}$ the change in entropy for the nth stream. Kalina ${ }^{13}$ has shown that 
if the cooling water is assumed to be the sink instead of the ambient temperature or ambient wet bulb temperature, an effective ambient temperature can be defined as:

$$
\begin{aligned}
T_{0}= & T_{e}\{2- \\
& \left.T_{e}\left[\ln \left(T_{i} / T_{e}\right) /\left(T_{i}-T_{e}\right)\right]\right\}
\end{aligned}
$$

where $T_{i}$ and $T_{e}$ are the inlet and outlet temperatures of the coolant sink in absolute units. For temperatures encountered in normal power production, $T_{0}$ can be approximated within hundredths of a percent by:

$$
T_{0}=\left(T_{1}+T_{e}\right) / 2
$$

i.e., the mean coolant temperature.

Note that, for a process, the outlet available energy is the inlet available energy plus the irreversibility. For example, for a process transferring heat from a stream at $T_{h}$ to a stream at $T_{c}$ in steady flow, the irreversibility will be:

$$
d I / d q=\left(T_{0} D T\right) /\left(T_{h} T_{c}\right)
$$

where all of the temperatures are in absolute units and DT is the temperature difference across which the heat is transferred, that is $T_{h}-T_{c}$.

An important observation is that if $T_{h}$ and $T_{c}$ are significantly greater than $T_{0}$, the irreversibility per unit heat transfer at fixed DT is significantly lower than if they are at temperatures near $T_{0} . \quad$ If $T_{h}$ and $T_{c}$ are about 1.5 times $T_{0}$ (typical of the heat addition process) the irreversibility per unit heat transferred at a fixed $T_{0}$ and DT will be $44 \%$ that of a heat transfer process in which $T_{h}$ and $T_{c}$ are approximately equal to $T_{0}$ such as the heat rejection process. This implies that closer approaches are advantageous (increase efficiency more) in the heat rejection process than in the heat addition process.

Kal ina ${ }^{13}$ graphically shows this relationship by plotting an "exergetic temperature", $T_{\text {ex }}$, instead of actual temperature on heat duty plots for heat exchange, where:

$$
T_{\text {ex }}=1-\left(T_{0} / T\right) \text {. }
$$


Then,

$$
d I / d q=D T_{\text {ex }}
$$

where $D T_{\text {ex }}$ is the difference in the hot and cold exergetic temperatures. For a more complete discussion see a basic engineering thermodynamics text (see Reference ${ }^{12}$ ).

\section{Methodology}

A realistic maximum can be $\mathrm{placed}$ on the work produced for a given resource using the ideas discussed in the previous section. If one assumes logical values for heat exchanger pinch-point temperature differences or log-mean temperature differences (LMTD's) and for rotating machinery isentropic efficiencies, the irreversibilities associated with the heat transfer and work processes in a cycle with the optimum match between working fluid and heat source and heat sink can be calculated. The work produced by a given cycle can be determined by subtracting from the available energy in the geofluid source, the irreversibility associated with each of the cycle devices: the heater, the turbine, the condenser (heat rejection) and the pump.

This analysis attempts to be generic in its application. The efficiency produced by this analysis is for the plant only. It does not include parasitic power associated with the heat rejection system, or the geothermal supply and injection system. These systems are separate and the impact of each may vary considerably depending on the particular application. The plant is a separate unit and can be considered separately. The choice of the type of heat rejection system and impact of the supply and injection system are left for a site-specific analysis.

\section{Results}

Restricting the analysis to liquid resources, a working fluid is postulated which will give close to the minimum irreversibility in each component with a realistic temperature difference in heat exchangers and realistic isentropic efficiency for turbines and pumps. Figure 1 shows the heat addition and heat rejection curves for the ideal working fluid, "unobtainium". For a given pinch 


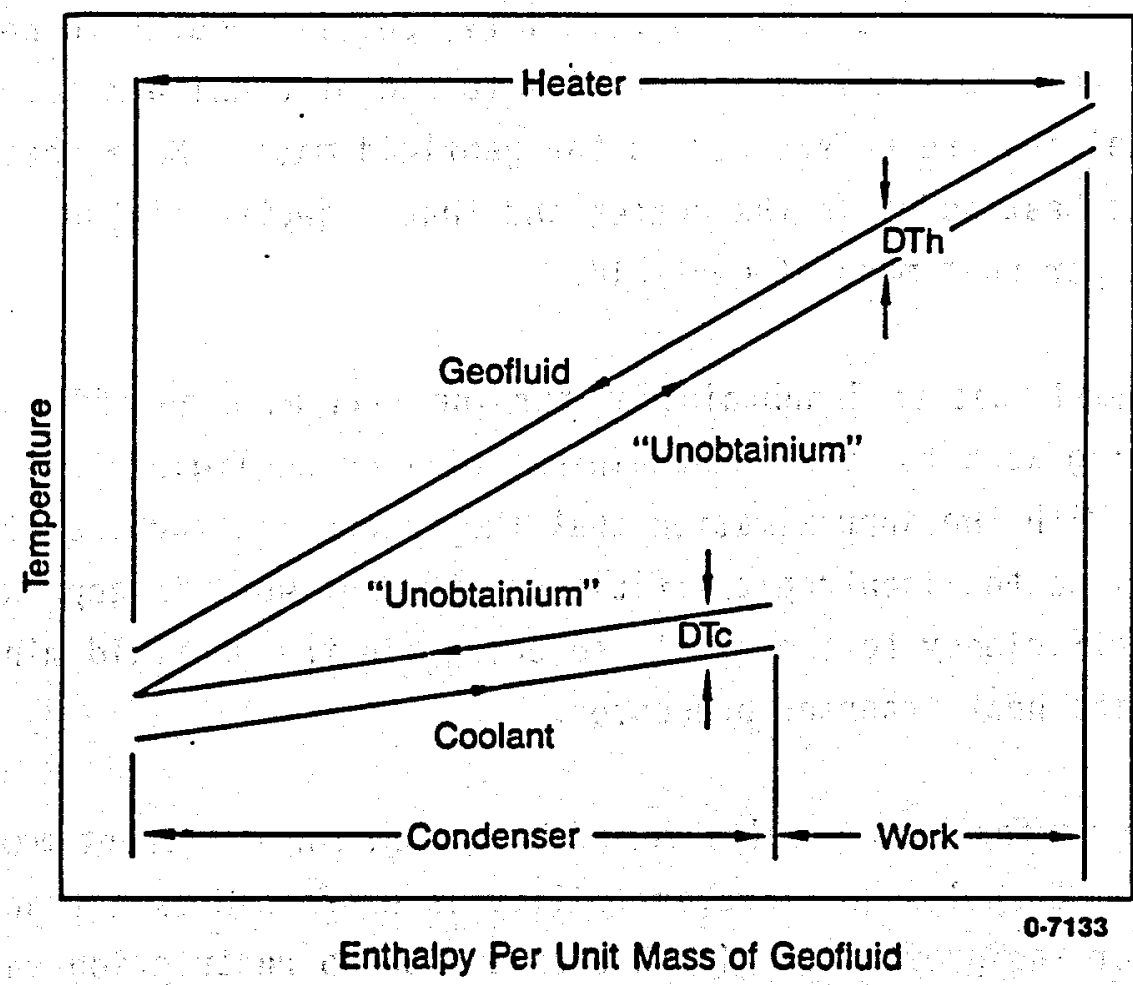

Figure 1. "Unobtainfum" cycle with unconstrained outlet temperature. 
point temperature difference, the minimum heat exchanger irreversibility occurs with a nearly constant temperature difference. With a fixed log-mean temperature difference (LMTD) for the exchanger, the appropriate average temperature difference for calculating the heat transfer in a heat exchanger with a varying temperature difference, the minimum irreversibility occurs with a slightly smaller temperature difference on the end of the heat exchanger nearer to $T_{0}$. For heater temperatures in the range of this study, for an LMTD of $10^{\circ} \mathrm{F}$, a temperature difference on the cold side of the exchanger of 8 to $9^{\circ} \mathrm{F}$ (on the hot side, 11 to $12.1^{\circ} \mathrm{F}$ ) gives slightly lower heater irreversibility than a uniform $10^{\circ} \mathrm{F}$ difference. That increase is between 0.6 and $1.2 \%$ of the heater irreversibility, and is thought to be not worth considering in order to simplify the problem to one of a uniform temperature difference. All enthalpies are referenced to the geofluid mass. Note that the difference between the heat added in the heater and that rejected in the condenser is the cycle net work per unit mass of geofluid.

It is further assumed that an "unobtainium" turbine will have an efficiency of $85 \%$ and that the pumping work for the "unobtainium" will be negligible when compared to the turbine work. With the approximation that the second law turbine efficiency is approximately equal to the isentropic efficiency, the net work is approximated by applying the turbine efficiency to the available energy in the geofluid minus the irreversibilities in the heat transfer processes.

Figure 2 shows the performance results for this system for different maximum resource temperatures. Each loss or irreversibility is expressed as a fraction of the available energy of the geofluid. (In this case with no restriction on geofluid outlet temperature, it was assumed that the geofluid could be reduced to ambient temperature.) These results are for a uniform temperature difference in both heat exchangers of $10^{\circ} \mathrm{F}$. That is, the pinch point and the $\log$ mean temperature difference are each $10^{\circ} \mathrm{F}$. At lower resource temperatures the fraction of the available loss due to heat exchange increases, indicating that smaller pinch points would be justified for lower temperature resources. Note that the condenser irreversibility is larger than the heater irreversibility because the heat exchange fluid temperatures are closer to $T_{0}$ as explained in a previous section. This would indicate the effectiveness of lower pinch points in the condenser than in the heater. This point has been explored by $B 1$ iem ${ }^{14}$ from a cost-effectiveness point 


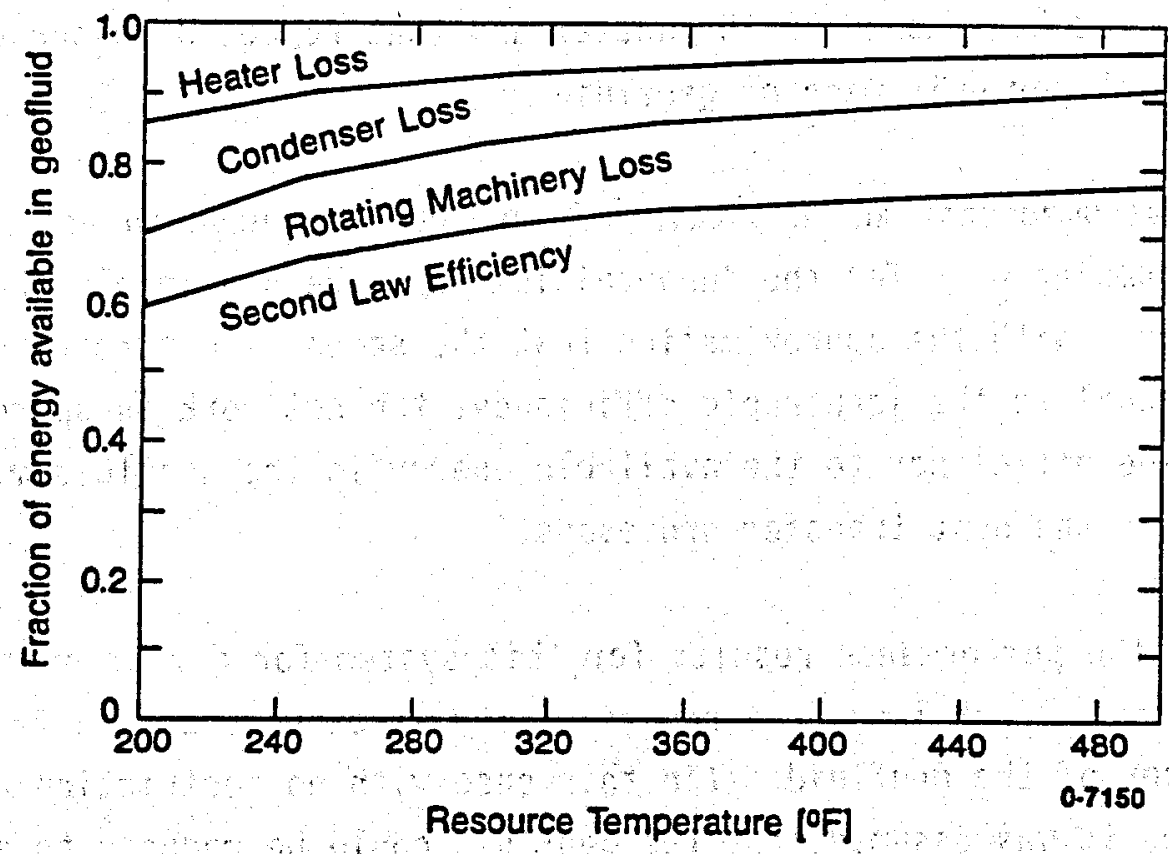

Figure 2. Efficiency of "unobtainium" cycle with unconstrained outlet temperature. 
point temperature difference, the minimum heat exchanger irreversibility occurs with a nearly constant temperature difference. With a fixed log-mean temperature difference (LMTD) for the exchanger, the appropriate average temperature difference for calculating the heat transfer in a heat exchanger with a varying temperature difference, the minimum irreversibility occurs with a slightly smaller temperature difference on the end of the heat exchanger nearer to $T_{0}$. For heater temperatures in the range of this study, for an LMTD of $10^{\circ} \mathrm{F}$, a temperature difference on the cold side of the exchanger of 8 to $9^{\circ} \mathrm{F}$ (on the hot side, 11 to $12.1^{\circ} \mathrm{F}$ ) gives slightly lower heater irreversibility than a uniform $10^{\circ} \mathrm{F}$ difference. That increase is between 0.6 and $1.2 \%$ of the heater irreversibility, and is thought to be not worth considering in order to simplify the problem to one of a uniform temperature difference. All enthalpies are referenced to the geofluid mass. Note that the difference between the heat added in the heater and that rejected in the condenser is the cycle net work per unit mass of geofluid.

It is further assumed that an "unobtainium" turbine will have an efficiency of $85 \%$ and that the pumping work for the "unobtainium" will be negligible when compared to the turbine work. With the approximation that the second law turbine efficiency is approximately equal to the isentropic efficiency, the net work is approximated by applying the turbine efficiency to the available energy in the geofluid minus the irreversibilities in the heat transfer processes.

Figure 2 shows the performance results for this system for different maximum resource temperatures. Each loss or irreversibility is expressed as a fraction of the available energy of the geofluid. (In this case with no restriction on geofluid outlet temperature, it was assumed that the geofluid could be reduced to ambient temperature.) These results are for a uniform temperature difference in both heat exchangers of $10^{\circ} \mathrm{F}$. That is, the pinch point and the log mean temperature difference are each $10^{\circ} \mathrm{F}$. At lower resource temperatures the fraction of the available loss due to heat exchange increases, indicating that smaller pinch points would be justified for lower temperature resources. Note that the condenser irreversibility is larger than the heater irreversibility because the heat exchange fluid temperatures are closer to $T_{0}$ as explained in a previous section. This would indicate the effectiveness of lower pinch points in the condenser than in the heater. This point has been explored by $B 7$ iem ${ }^{14}$ from a cost-effectiveness point for the supercritical Rankine cycle. When the heat exchange irreversibility and the 
rotating machinery irreversibility fractions are subtracted from unity, the second law efficiency (net plant work divided by the available energy in the geofluid) remains. For this system, the efficiency varies from about 65 to $75 \%$ depending on the resource temperature, for this LMTD and rotating machinery efficiency.

In many cases, the minimum temperature to which the geofluid can be cooled is limited by concerns over deposition of silica. Calculations for the concentration of silica based on the solubility of quartz in water at the resource temperature and the temperature of precipitation of amorphous silica at this concentration, give an estimate of the temperature at which silica deposition will occur. (See Reference 15.) Actually, there are many other variables including concentration of other components in the solution, but this gives an approximate value which can be used in a generic analysis. Table 1 indicates the results of this calculation. The minimum geofluid outlet temperature increases as the resource temperature increases and is less than the ambient temperature, $T_{0}$ at resource temperatures below $280^{\circ} \mathrm{F}$.

Figures 3 and 4 depict this case with a single heater and single condenser. It is impossible to maintain constant temperature differences in both the heater and condenser as was done in the previous case. It was decided to minimize irreversibilities in the condenser rather than in the heater by maintaining a constant temperature difference in the condenser. Then the temperature difference in the heater is not uniform. The temperature difference on the hot end of the heater is changed to obtain LMTD's of $10^{\circ} \mathrm{F}$. If the "unobtainium" temperature leaving the condenser had been raised, the additional condenser irreversibility would have been more than the decrease in the heater irreversibility. This would have resulted in a net increase in cycle irreversibility. The net plant second law efficiency with this restriction was between 55 and $60 \%$. The heater irreversibility is increased over the case with no 1 imit in outlet temperature. The shapes of the curves in Figure 4 (discontinuous slopes) result from the fact that there is no outlet temperature 1 imit below $280^{\circ} \mathrm{F}$ and the 1 imit temperature increases as the resource temperature increases. (Below that temperature, $280^{\circ} \mathrm{F}$, the curves are identical to Figure 2.)

In the case of a restricted minimum geofluid temperature, adding internal recuperation allows the heater irreversibility to be decreased substantially (although there is an added irreversibility associated with the recuperative heat 
Table 1. Silica deposition 1 imits

\begin{tabular}{|c|c|}
\hline $\begin{array}{c}\text { Resource } \\
\text { Temperature }\end{array}$ & $\begin{array}{c}\text { Silica } \\
\text { Deposition } \\
\text { Temperature }\end{array}$ \\
\hline$[\mathrm{F}]$ & {$[\mathrm{F}]$} \\
\hline & \\
\hline 200 & -- \\
\hline 250 & -- \\
\hline 300 & 103.07 \\
\hline 350 & 149.35 \\
\hline 400 & 197.23 \\
\hline 450 & 246.78 \\
\hline 500 & 298.09 \\
\hline
\end{tabular}




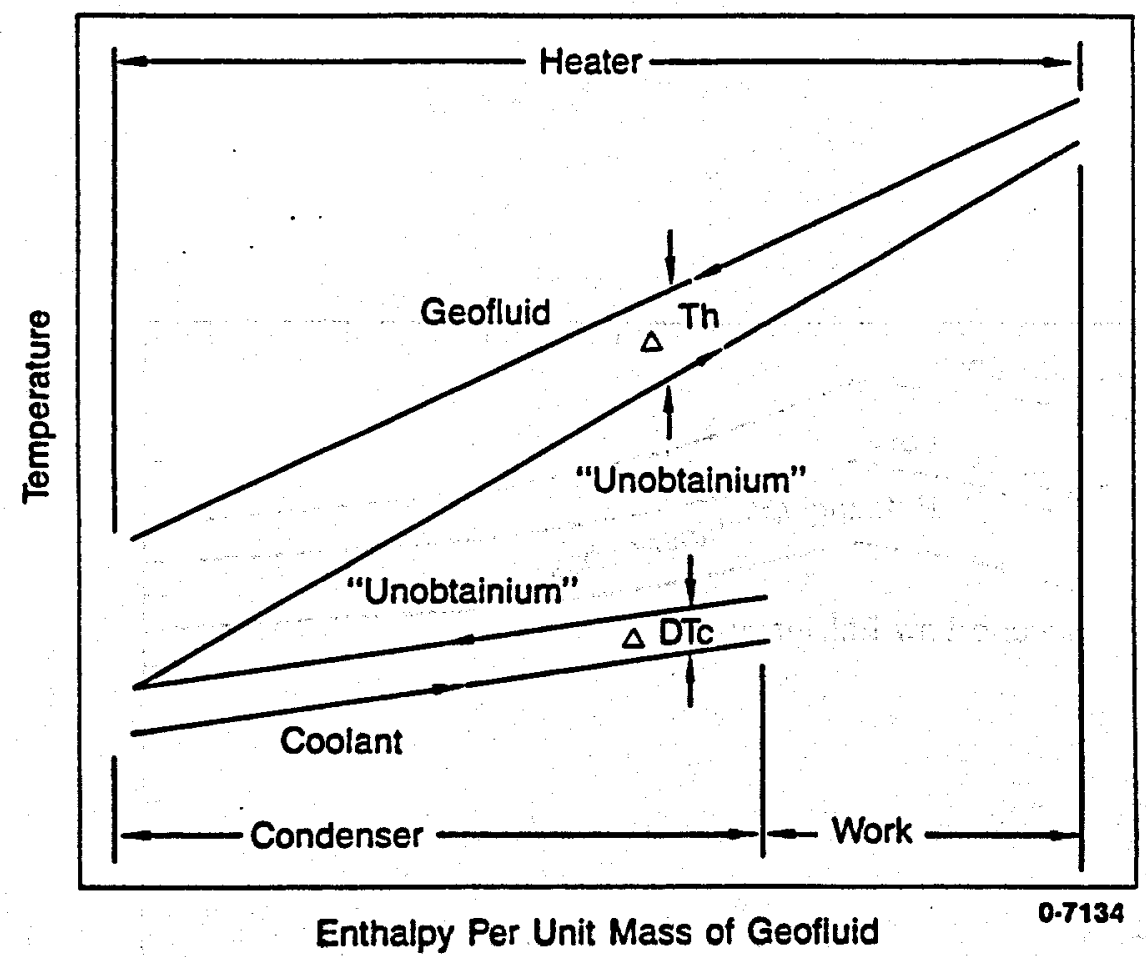

Enthalpy Per Unit Mass of Geofluid

Figure 3. Unobtainium" cycle with constrained outlet temperature. 


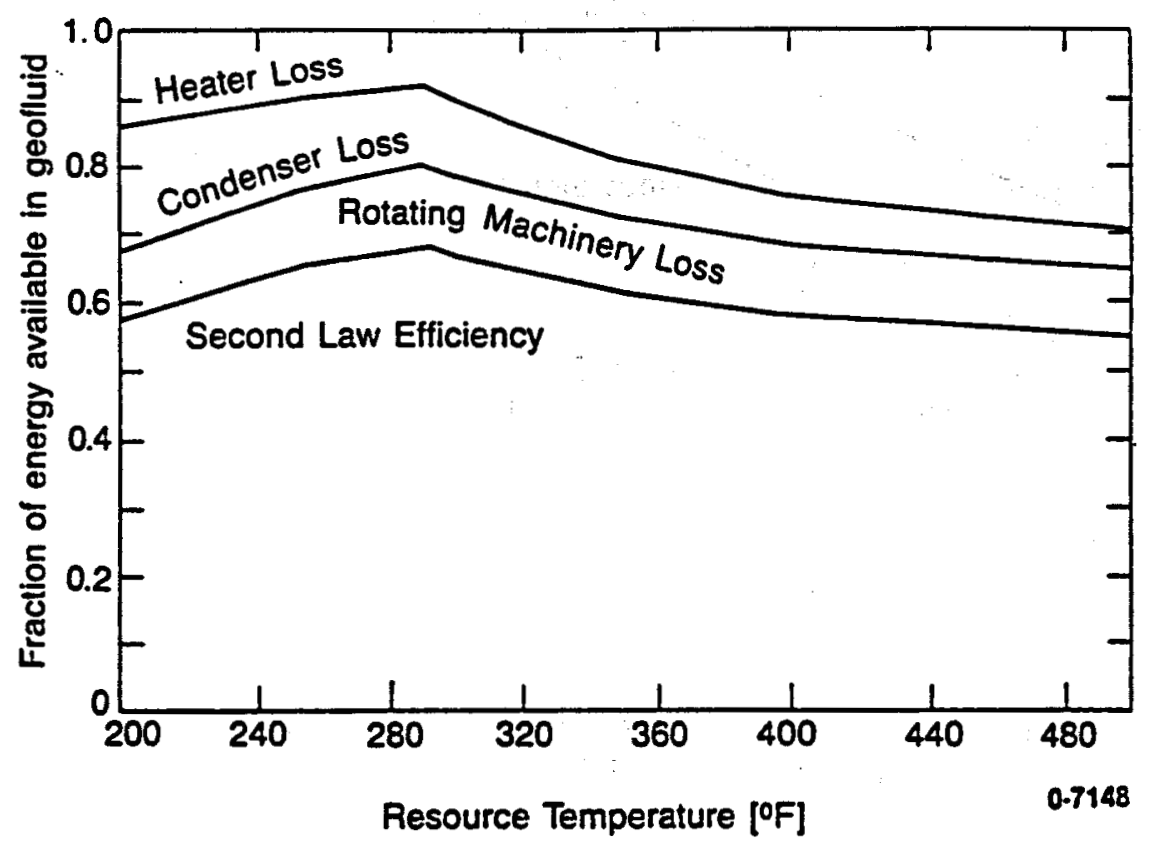

Figure 4. Efficiency of "unobtainium" cycle with constrained outlet temperature. 


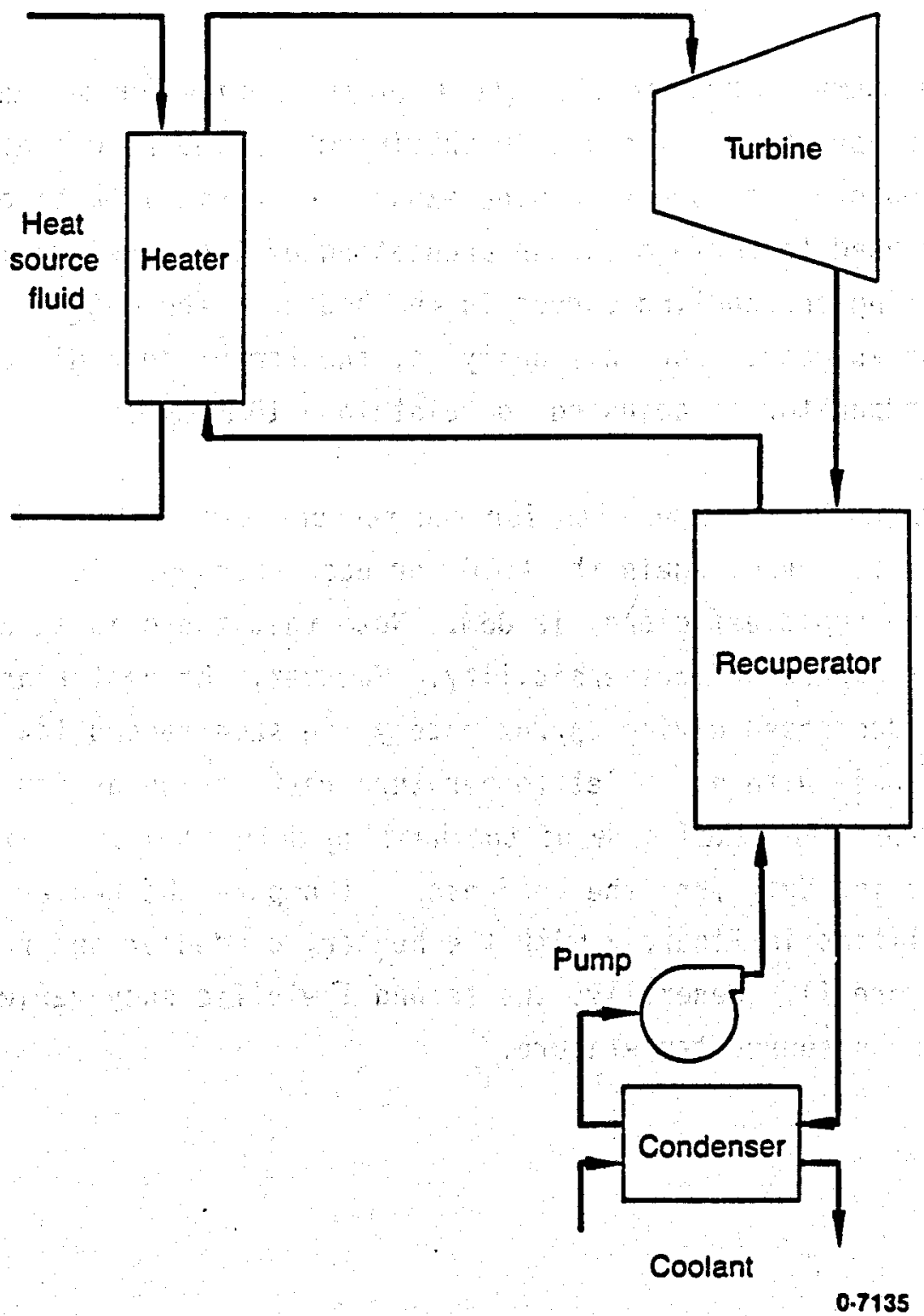

Figure 5. Recuperated rankine cycle. 
transfer.) These results have been shown by Demuth and Kochan ${ }^{5}$ for a Rankine cycle using turbine exhaust to recuperatively heat the working fluid. Figure 5 shows a schematic diagram of such a system. Another recuperative scheme used in utility steam plants is feedwater heating with steam bled from intermediate turbine stages. Demuth and Kochan considered this method of recuperation but found, in general, results were no better than with the turbine exhaust recuperation which is somewhat less complex.

Figure 6 shows the temperature enthalpy (heat duty) diagram for an "unobtainium" cycle with internal recuperation. The hot "unobtainium" in the recuperator would come from the expansion process as hot turbine exhaust or a small turbine bleed stream. This heat is used to perform enough preheating of the working fluid to give an ideal match of heating and cooling curves in the heater. The match in the recuperator may not be as good. For this analysis, the temperature difference at the hot end of the recuperator is adjusted to maintain a $10^{\circ} \mathrm{F}$ LMTD.

Figure 7 shows the performance results for the recuperated cycle with a geofluid outlet temperature limit. Here, again the LMTD for each exchanger is $10^{\circ} \mathrm{F}$ and the rotating machinery isentropic efficiency is $85 \%$. Note that there is an added loss for this system, the recuperator irreversibility. However, the heater and condenser irreversibilities are decreased giving approximately the same second law plant efficiency as for the case with no outlet temperature restriction as found in Reference 5. The recuperator takes some of the heating duty from the heater and some of the heat rejection duty from the condenser. (Compare the heater and condenser irreversibilities in Figure 2 with the heater, condenser and recuperator irreversibility in Figure 7). Generally, the second law efficiency varies from 65 to $75 \%$ depending on the resource temperature. 


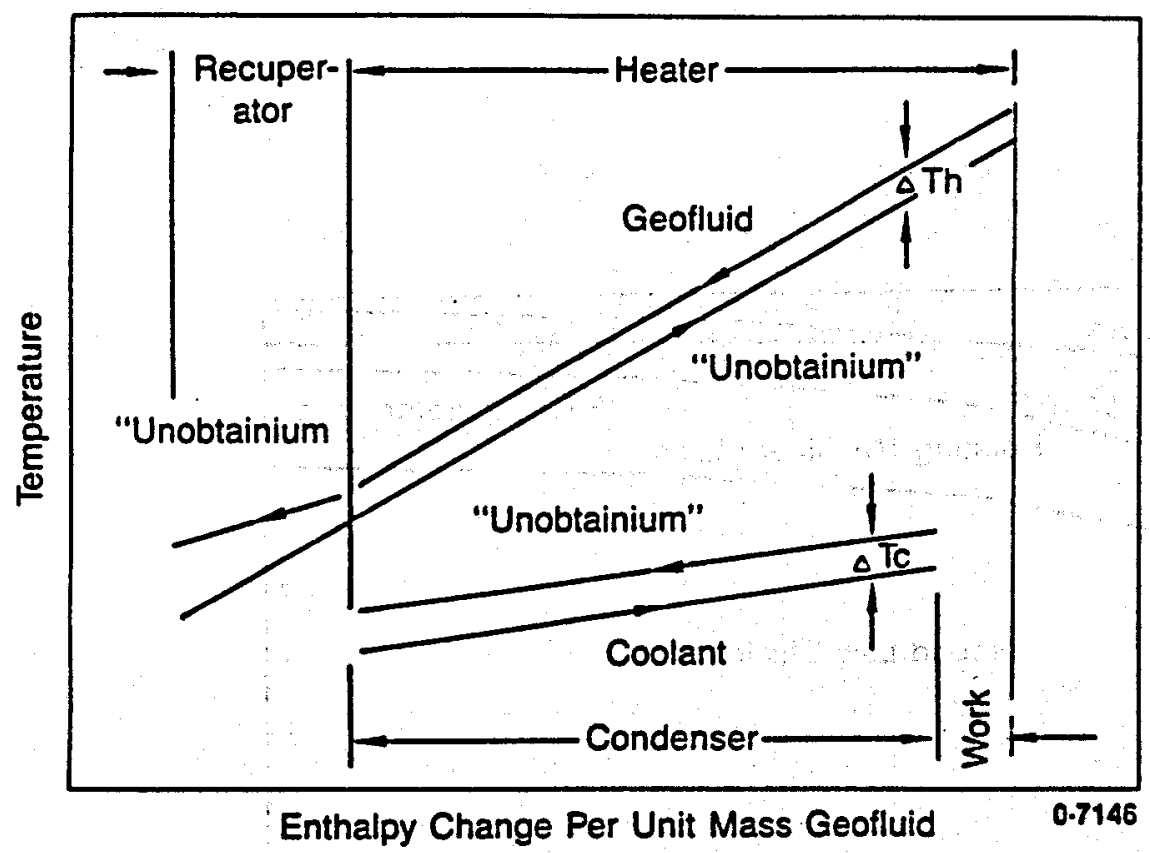

Figure 6. Recuperated "unobtainium" cycle with Constrained Outlet Temperature. 


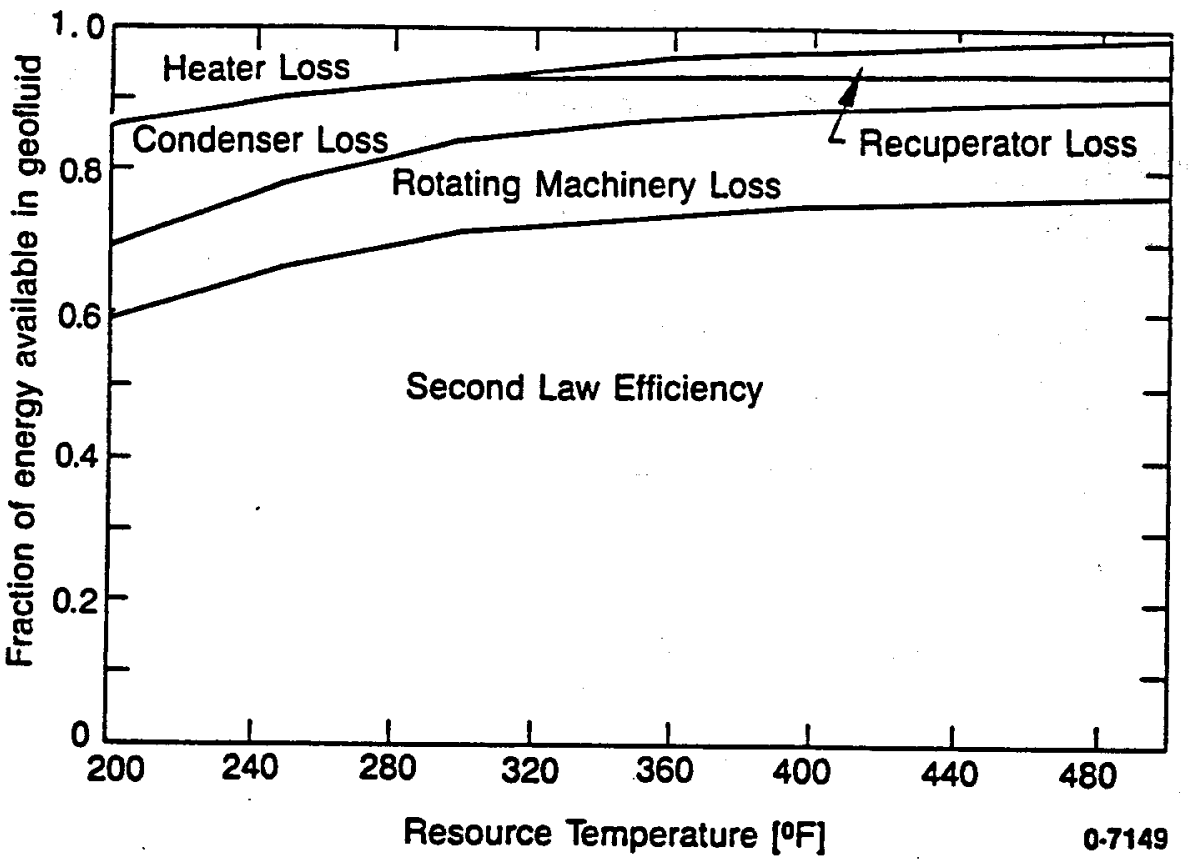

Figure 7. Efficiency of recuperated "unobtainium" cycle with constrained outlet temperature. 


\section{ADVANCED SYSTEM PERFORMANCE}

How close do the latest advanced cycles approach the maximum plant efficiency defined in the previous section? It is convenient to separate systems which have a limit on the geofluid outlet temperature from those which do not. In the following section, systems with limited geofluid outlet temperature will be considered. Most of the systems have been optimized for operation under this constraint. The second section considers systems without this constraint, the Trilateral cycle and the Heat Cycle concept of turbine expansion "through-the-dome" ${ }^{16}$ are examples of this type of system.

\section{Systems with Outlet Temperature Constraints}

Three proposed systems are considered to illustrate the methods which use real fluids to approach the behavior of "unobtainium." A supercritical Rankine cycle with exhaust gas recuperation and a Kalina System 12 are discussed in some detail and the Polythermal Technologies Low Temperature Energy System is also discussed, but not to the same degree because there is less in the literature concerning specific state-point data. State points for the supercritical Rankine cycle and the Kalina System 12 are given in Reference 17 where the two systems are compared under the same assumptions. More detail on individual processes in the Kalina System is given in Reference 9 and the supercritical Rankine cycle illustrated here is discussed in earlier work from the Heat Cycle Research program ${ }^{4.5 .6}$. The results quoted here are for a liquid resource at $376^{\circ} \mathrm{F}$.

The path pursued in the Heat Cycle program has been to use a Rankine cycle as depicted in Figure 5 and approximate the nearly linear heating curve of working fluid by operating at pressures above the critical point. The use of a mixture allows critical pressures and temperatures to be matched with the given resource maximum temperature and remain at moderate pressures (for example, below the rating for 600 psi flanges).

Figure 8 show a temperature-enthalpy plot for the heat exchange processes of the cycle. (This representation is used rather than the exergetic temperature-enthalpy because it is more familiar to designers. If the exergetic temperature had been used, the area between curves would be directly proportional to the heat transfer 


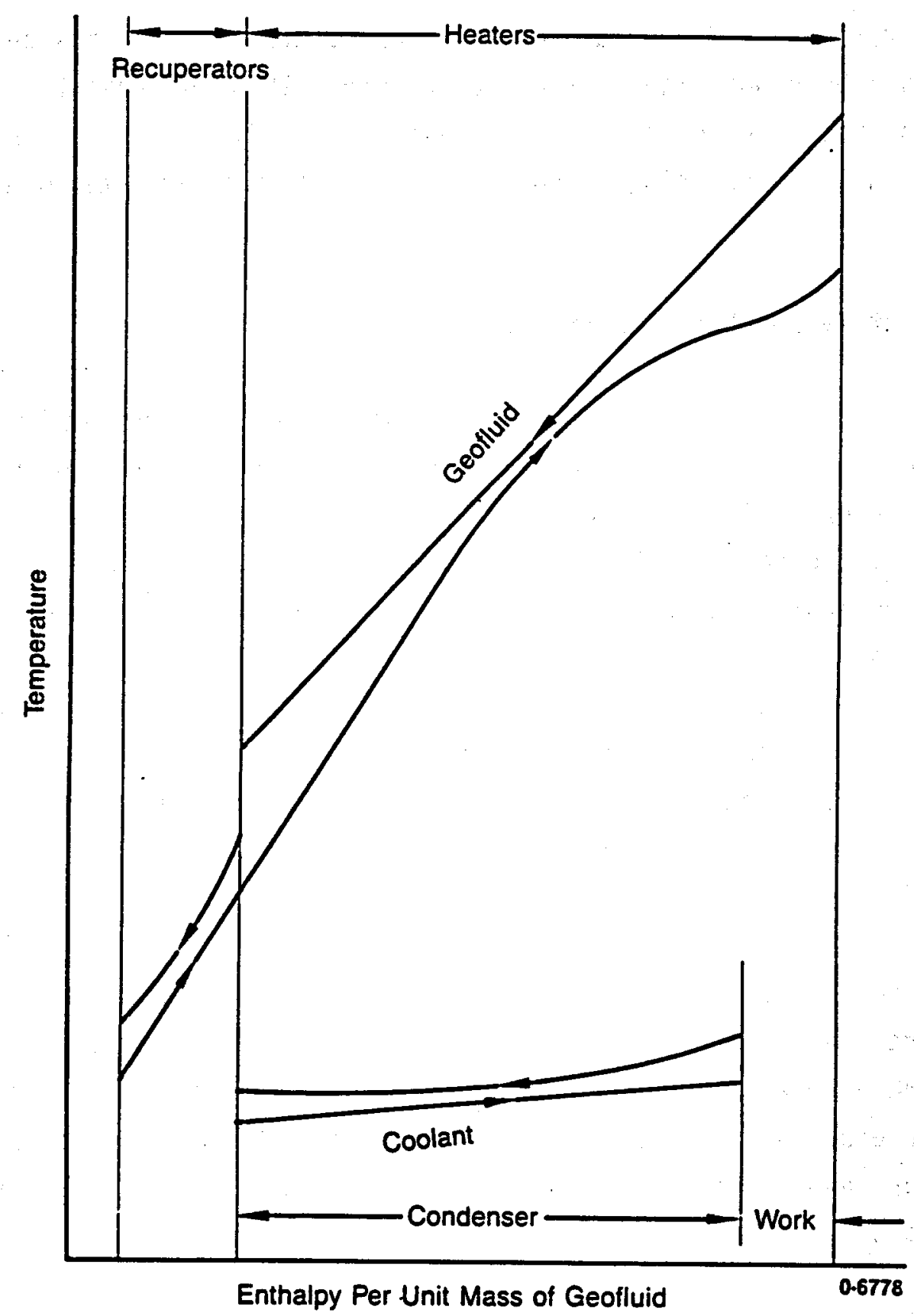

Figure 8. Temperature-enthalpy diagram for supercritical rankine cycle. 
irreversibility). In this diagram, as discussed in the background section, a temperature difference at the hot end of the heater represents approximately half the irreversibility of the same temperature difference in the condenser because of their relation to $T_{0}$. Note that the largest temperature differences are near the hot and cold ends of the heater. The enthalpy change of the condenser is lined up with the heater because the difference in heat transferred is the net work for the cycle. The temperature difference in the condenser is practically constant. This is a result of using a mixture for a working fluid and achieving integral condensation in countercurrent flow. The recuperator, which heats the working fluid by using turbine exhaust has a relatively small heat duty and a nearly constant temperature difference resulting in a small absolute irreversibility. The primary inefficiency is the large temperature difference near the cold end of the heater.

Another advanced system operating under the same constraints is the Kalina System 12. 9 Figure 9 shows a schematic diagram of this system. This system was unveiled in January 1989 and Exergy, Inc. has, since that time, developed a newer system with higher performance and more complexity which might be desirable for a large installation. The Kalina system uses a mixture of water and ammonia as the working fluid. Because the working fluid becomes wet as it expands, a reheat stage and second turbine are required. Figure 10 shows a temperature-enthalpy diagram for this system. Note that because the superheater and reheater heat the working fluid through a similar temperature range, irreversibilities are minimized by splitting the geofluid flow between these units. (This is the rightmost part of the figure. Note that the individual heat exchangers are identified on both figures). The initial vaporization of the working fluid is split between the geofluid in HE-3 and turbine exhaust in HE-4. (The discontinuity in slope of the heating curve of the working fluid is a result of the split flow). This is necessary to maintain small temperature differences in HE-5 while avoiding a temperature pinch in HE-3. Again the condenser is lined up with the external heater train and the net work is shown as the difference between the heat transfer in and out.

Comparing Figures 8 and 10 show that there is little difference in heat exchange irreversibility between the two systems. Temperature differences in the heating processes are similar for the two systems. In the System 12, more of the heating duty is done recuperatively, to avoid temperature pinch at the cold end of the heater. This results in a larger irreversibility in the System 12 . It is 


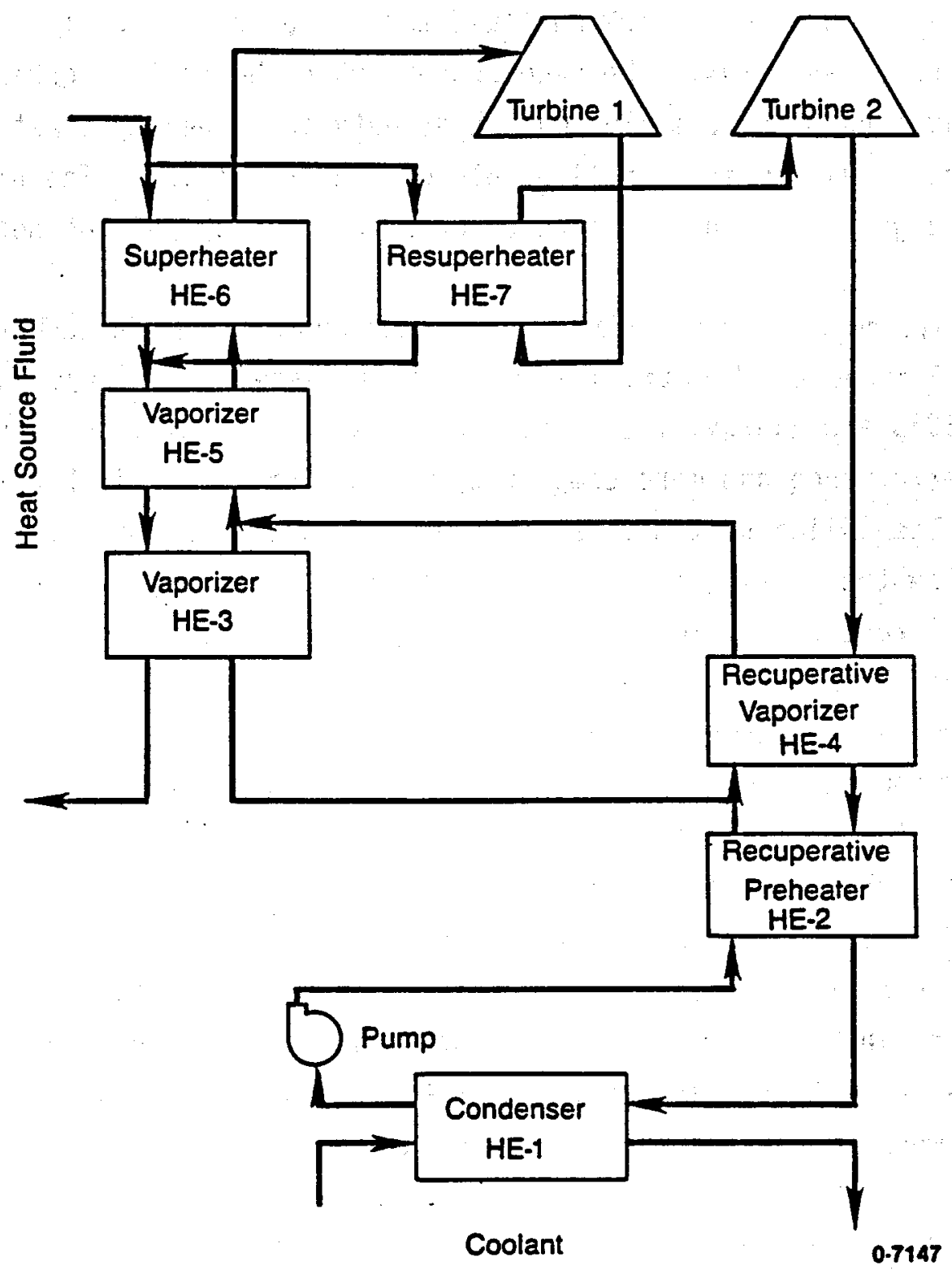

Figure 9. Kalina system 12 . 


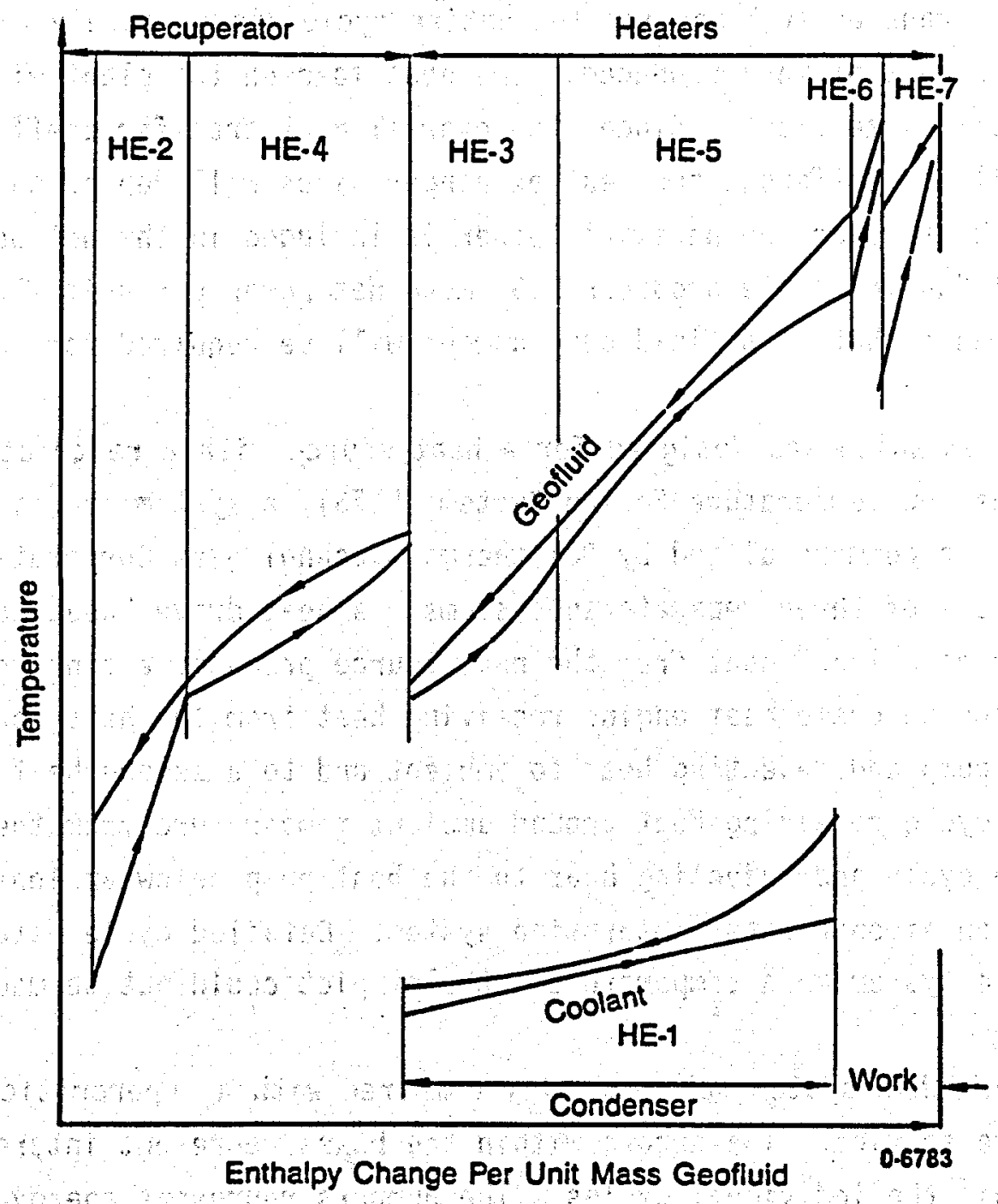

Figure 10. Temperature-enthalpy diagram for kalina system 12. 
interesting to note that per unit of work produced approximately $25 \%$ more heat is transferred in the System 12 than in the supercritical Rankine system.

Figure 11 shows a comparison between the supercritical Rankine cycle and the Kalina System 12. In the schematics, each system produces the same amount of net work. Note that the Kalina system 12 requires three times the amount of recuperative heat transfer $\left(Q_{r}\right)$ and for the entire cycle approximately $26 \%$ more heat is transferred per unit of work produced. The heat load on the plant will be $26 \%$ greater for the same size plant. Since, the overall heat transfer coefficients for the two plants will be different the heat exchanger sizes will depend on more than heat load. When heat rejection parasitic power is included in the net power output, the supercritical Rankine cycle produces $2.5 \%$ more net power per unit flow rate of geofluid. This means that less field development will be required for this option.

The other system which was designed for a heat source with a restricted outlet temperature is the Low Temperature Engine System (LTES), a system conceived by J. H. Rosenblatt and being commercialized by Polythermal Technologies Corporation. ${ }^{10}$ This system consists of three separate subsystems: a heat-driven heat pump (heat amplifier) receiving primary heat from the heat source produces a sink below ambient temperature; a Rankine cycle heat engine receiving heat from the heat source as well as from the heat pump and rejecting heat to ambient and to a second heat engine; and a second Rankine cycle receiving heat around ambient temperature from the heat pump and first Rankine cycle and rejecting heat to the heat pump below ambient. The heat pump proposed is an ammonia-water absorption system. Detailed cycle data was not available for this system so a temperature-enthalpy plot could not be made.

Figure 12 shows this system schematically compared with a supercritical Rankine cycle for the same service. The arrows within the boxes represent internal recuperation within the individual cycles. The numbers represent energy flows for a net work output of one energy unit. The results quoted in this report are for a system using a partially flashed resource which contains $13 \%$ by mass steam at a temperature of $450^{\circ} \mathrm{F}$ (corresponding to a downhole temperature of approximately $540^{\circ} \mathrm{F}$ ). Notice again, that there is a large amount of recuperative heat transfer for the LTES compared with the Rankine cycle. The results quoted here have not been optimized with respect to cost or performance and, therefore, should be used to show a general trend rather than quantative results. 


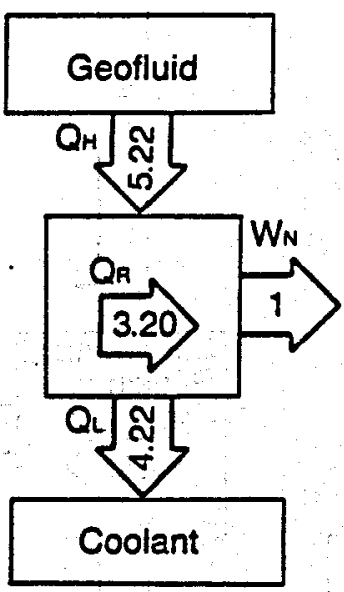

Thermal Efficiency

Second-Law Efficiency $19.1 \%$

$69.7 \%$

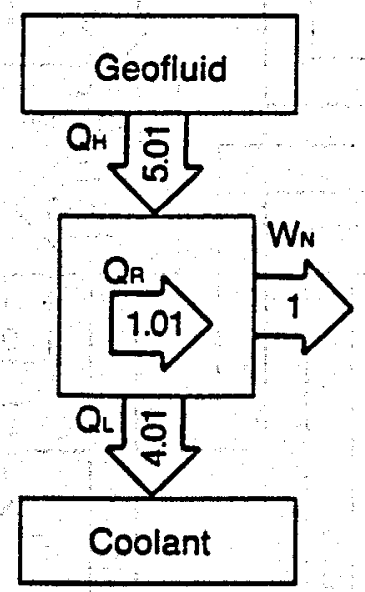

$20.0 \%$

$73.1 \%$

Net Geofluid Effectiveness 10.76 whellb geo 11.03 whe/lb geo (Including Heat Rejection)

Total Heat Transferred/Net Work $12.64 \quad 10.02$

Kalina "System 12"

Supercritical Rankine Cycle

0.7143

Figure 11. Comparison between cycles. 


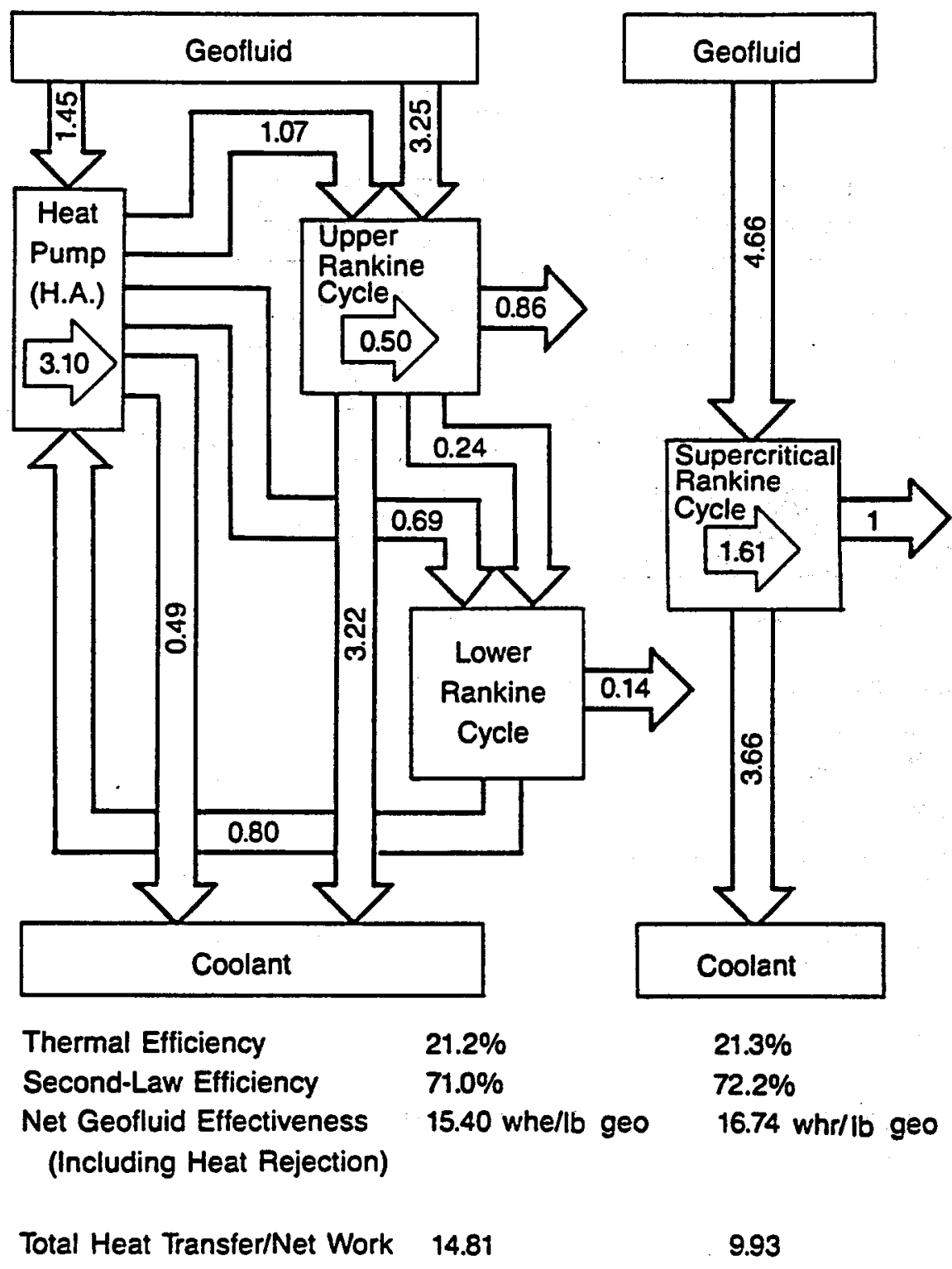

Low Temperature Engine System Supercritical Rankine Cycle (Polythermal Technologies Corporation) 0.7144

Figure 12. Comparison between two other cycles. 


\section{Systems without Outlet Temperature Constraints}

Some applications have no constraint on the geofluid outlet temperature. The Trilateral cycle is proposed for a hot-dry rock power plant by the United Kingdom Department of Energy and discussed in detail in Reference 11. This is the cycle called the "wet-to-dry" cycle in an earlier work by Elliott. ${ }^{18}$ Figure 13 shows the cycle on a temperature-entropy diagram. The cycle operates by heating a liquid to its boiling point (somewhat below its critical point) and then expanding it through the two-phase region to vapor at the condenser pressure. This is possible with fluids that have a retrograde saturated vapor lines (that is, entropy decreases as temperature decreases) such as butane and the heavier hydrocarbons.

An alternative scheme was proposed by Demuth ${ }^{16}$ which involves the use of a standard supercritical Rankine cycle in which the fluid is heated past the critical temperature and then expanded through the two-phase region to essentially saturated vapor at the turbine outlet state. Figure 14 shows a temperature entropy diagram for this supercritical cycle. Demuth concluded that the vapor expanded through the turbine would stay in a metastable state and that condensation would not occur. This conclusion is being investigated with nozzle tests at the Heat Cycle Research Facility.

Figure 15 shows the temperature enthajpy diagram for the two cycles. Note that the Trilateral cycle has lower irreversibilities at the higher temperatures within the cycle while the Supercritical Rankine cycle has lower irreversibilities at the lower temperatures and during heat rejection. The latter al so takes more heat from the source fluid. The result is a $3 \%$ improvement in performance for the Supercritical Rankine cycle over the Trilateral cycle.

Figure 16 shows these real cycles on a plot of the theoretical efficiency of a system with an unconstrained outlet temperature (Figure 2). Note that both of the cycles considered are close to the theoretical maximum plant efficiency as predicted in the first part of the report. It should be noted that when the cooling parasitic associated with a wet cooling tower is added, the supercritical Rankine cycle has a net geofluid effectiveness of $13.015 \mathrm{w} \mathrm{hr} / 1 \mathrm{~b}$ while the Trilateral cycle has a value of $12.652 \mathrm{w} \mathrm{hr} / \mathrm{lb}$. Part of this increase in effectiveness is a result of the 


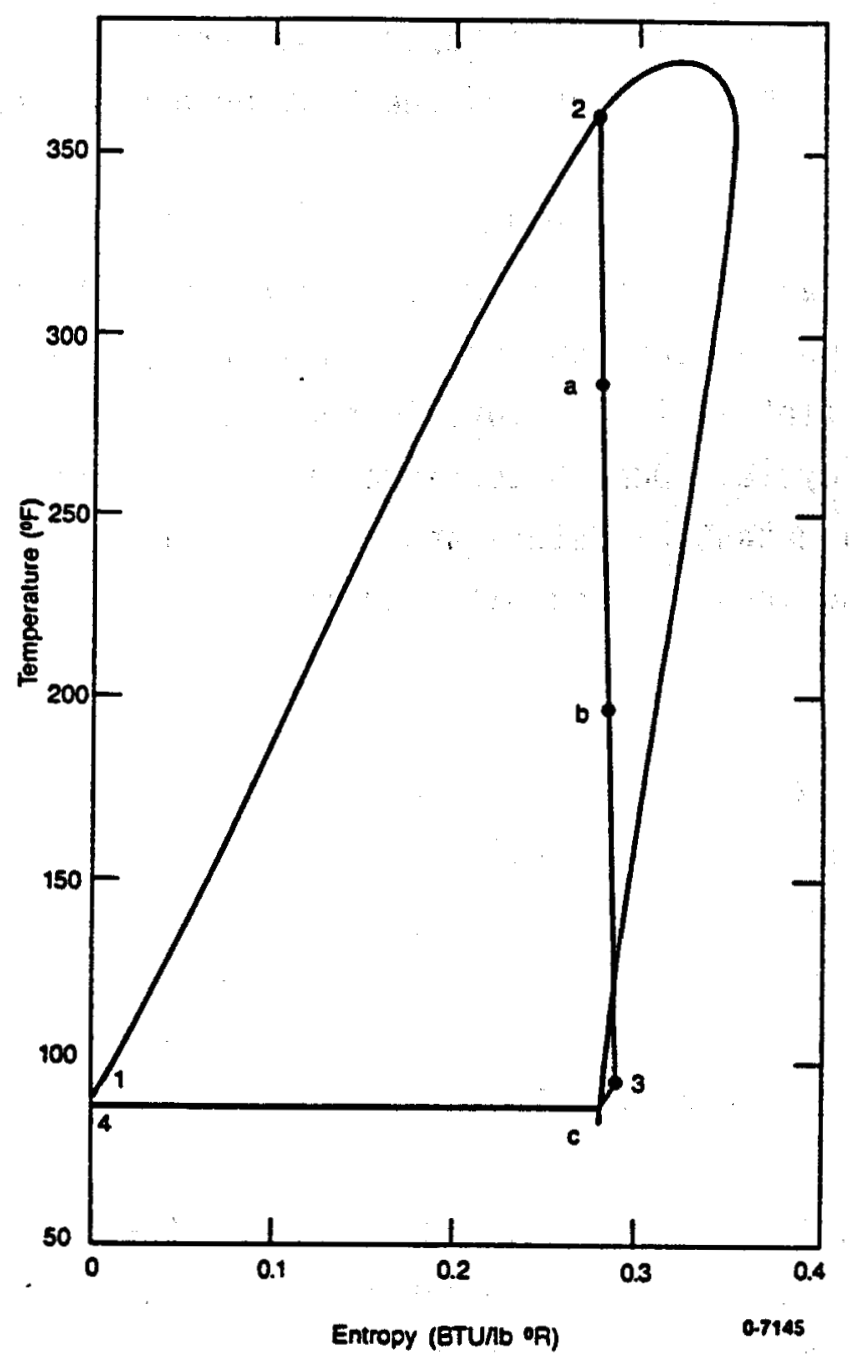

Figure 13. The trilateral cycle. 


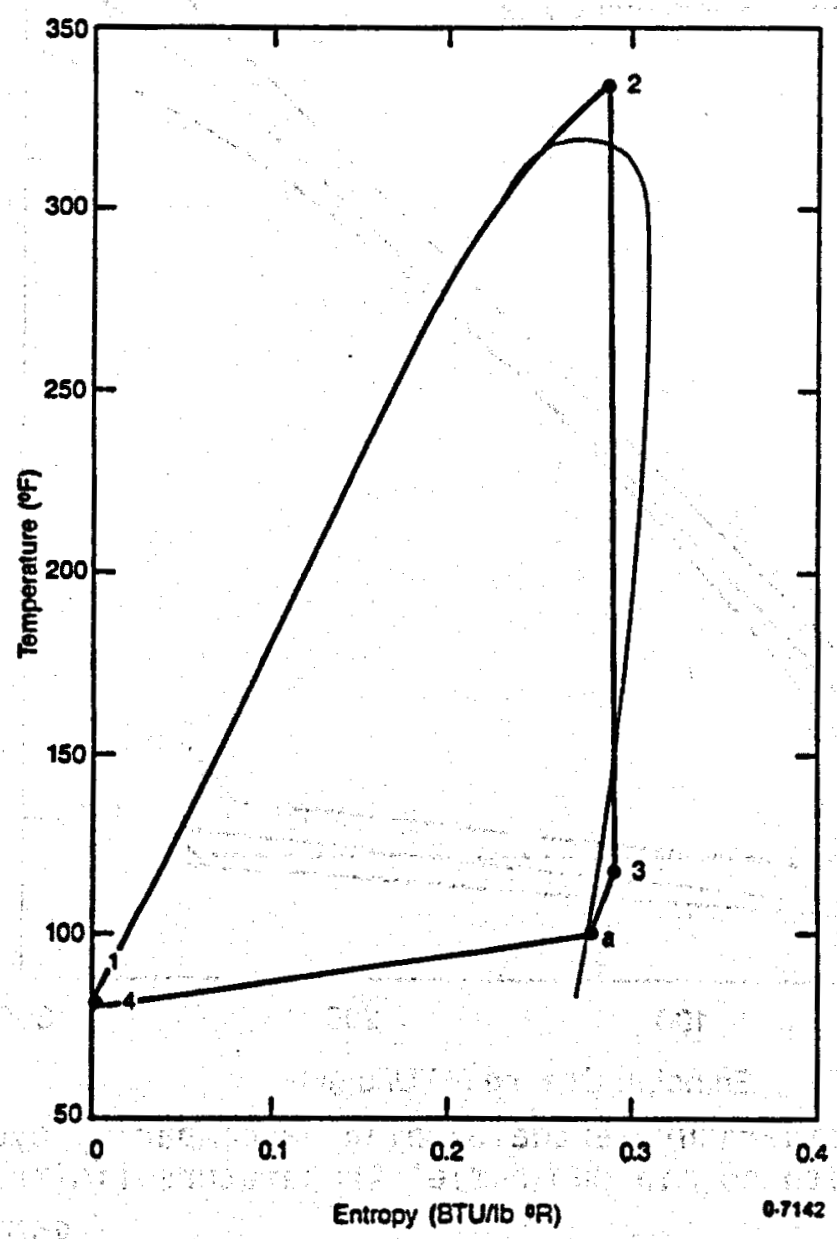

Figure 14. Supercritical rankine with expansion "through-the-vapor-dome." 


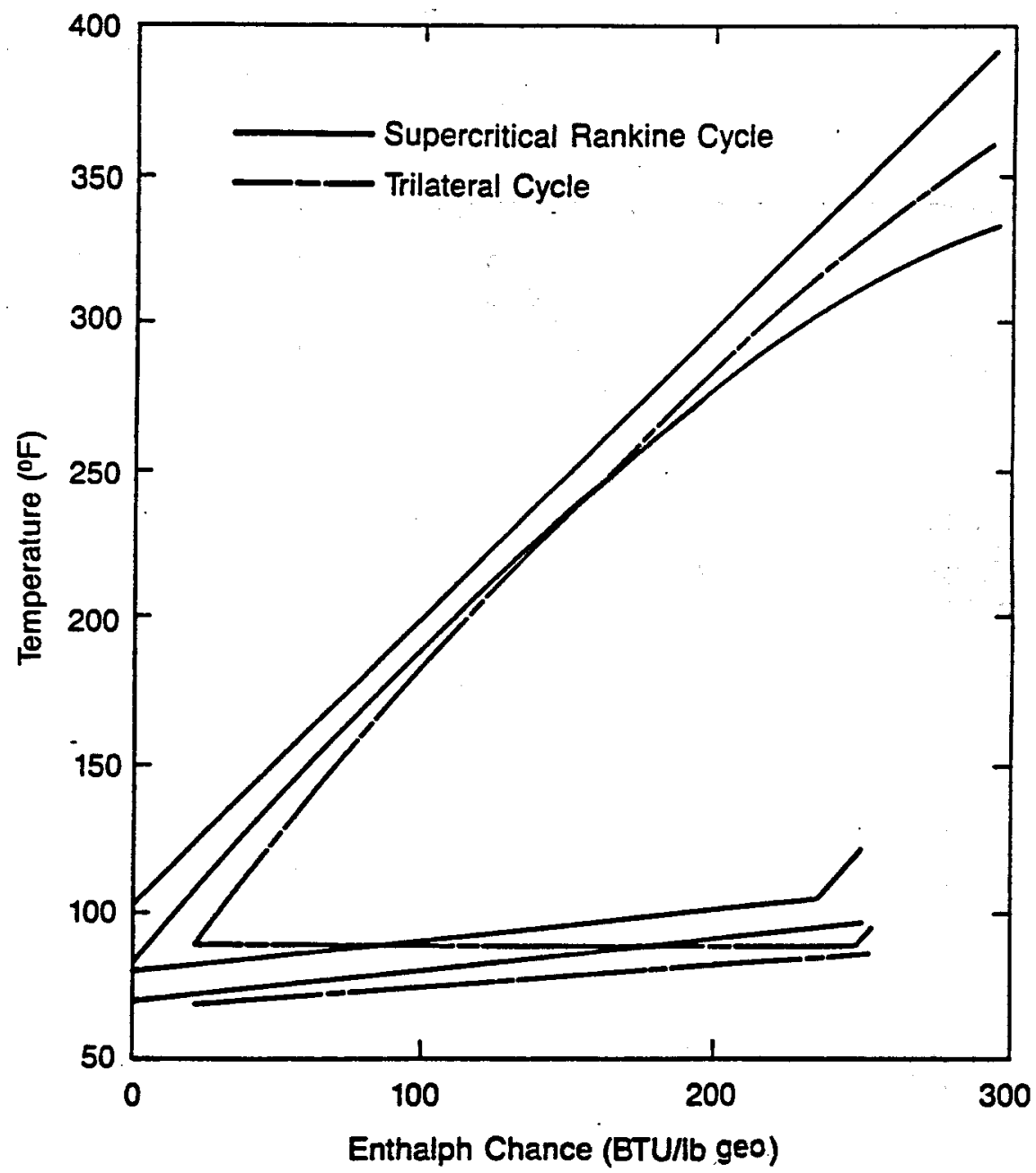

Figure 15. Temperature-enthalpy diagram comparing cycles - with no minimum outlet temperature limits.

0.6776 


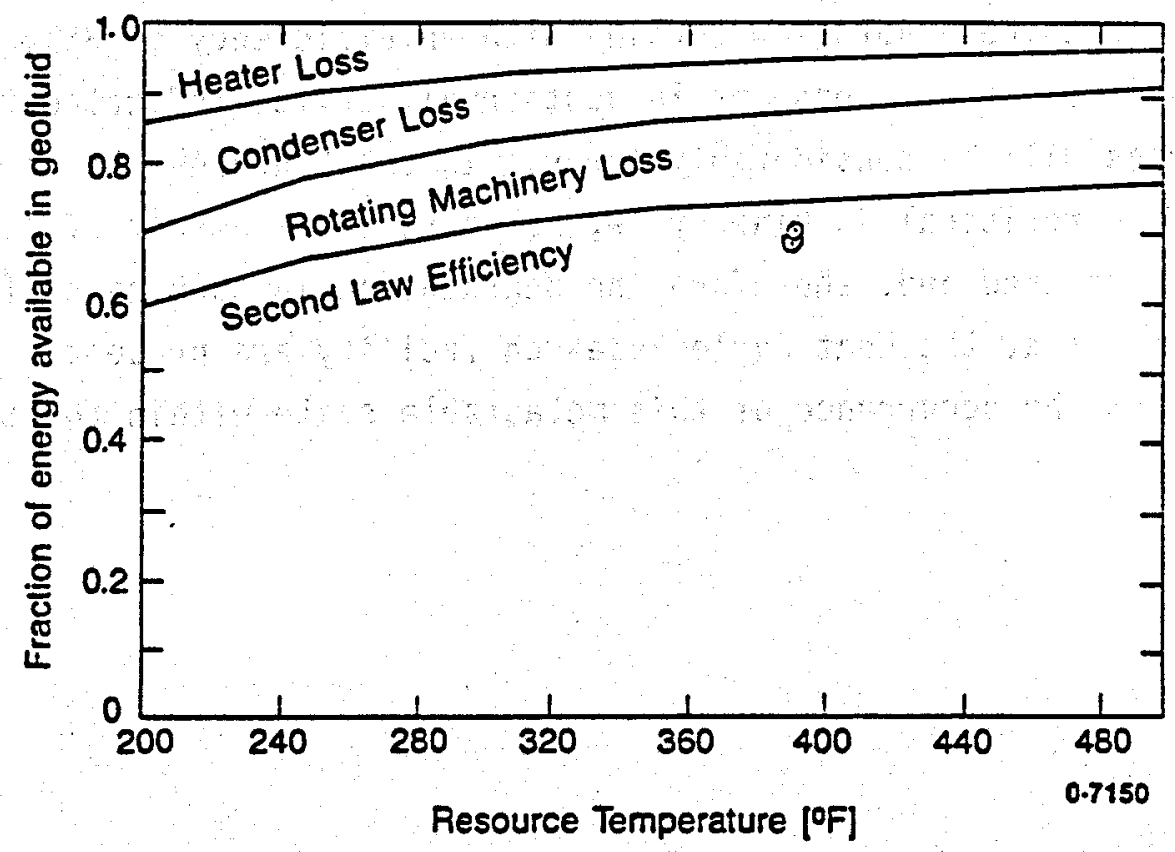

Figure 16. Comparison between cycles with no minimum temperature limit. 
countercurrent, integral condensation of a mixture in the Rankine cycle compared to the condensation of pure pentane in the Trilateral cycle.

There appear to be potential problems in executing the Trilateral cycle which are not present in the Supercritical Rankine cycle. Because of the large ratio of inlet to outlet volume during the expansion process and the fact that the expanding working fluid is a two-phase mixture, three expanders in series are proposed for the trilateral cycle. State points on Figure 13 labeled $a$ and $b$ represent the intermediate points between expanders. This will entail the movement of a two-phase mixture from one unit to another with the inherent added pressure drop and potential separation of the phases. The calculations for the Trilateral cycle also assume extremely high efficiencies for the expanders. The two high pressure expanders are to be helical screw expanders with efficiencies of 70 and $78 \%$ respectively. The low pressure expander is to be a Rotoflow turbine with an efficiency of $85 \%$. Past experience with helical screw expanders in geothermal service indicated that the assumed efficiencies will be considerably lower. In the "Through-the-Dome" expansion of the Supercritical Rankine cycle, no appreciable amount of liquid is expected to be encountered and, therefore, no degradation in turbine performance is expected. Experiments at the Heat Cycle Research facility are presently being conducted to confirm the occurrence of this metastable state within the turbine. 


\section{CONCLUSIONS}

Figure 17 summarizes the second law efficiencies for these systems together with estimates from References 7 and 8 for flash steam plants and for a $p l$ ant with the Heber Binary technology at a slightly higher resource temperature. The theoretical curves are for heater LMTD's between 12 and $16^{\circ} \mathrm{F}$; condenser LMTD's between 8 and $10^{\circ} \mathrm{F}$ and recuperator LMTD's 12 to $13^{\circ} \mathrm{F}$. Within these ranges, the results do not change noticeably. This is the range of the LMTD's for the systems pictured in Figures 8 and 10. These results indicate that all of these advanced technologies have the potential to significantly improve on current technology and each has the reasonable expectation of approaching the maximum second law plant efficiency indicated by the analysis presented here.

The primary result of this study is that there is a practical limit to the plant performance. In addition, it is shown that the advanced systems shown here do approach this limit. Each system has advantages and disadvantages. The power plant designer/operator must weigh these advantages and disadvantages and in combination with economic and site-specific constraints select the power system which best meets the requirements for that application.

Summarizing the results of this report:

With LMTD's around $10^{\circ} \mathrm{F}$ (close to a practical $1 \mathrm{imit}$ ) and turbine efficiencies of $85 \%$, net plant second law efficiencies of 65 to $75 \%$ are possible.

Increasing these efficiencies are expected to be difficult without large increases in heat exchanger size or improved turbine efficiencies.

Small approach temperature differences and LMTD's in the heat rejection heat exchange process reduce irreversibilities more than small approach temperature differences in the heating process. Similarly, in the heating process, smaller temperature differences on the cold end of the unit will reduce irreversibilities more than small temperature differences on the hot end. 


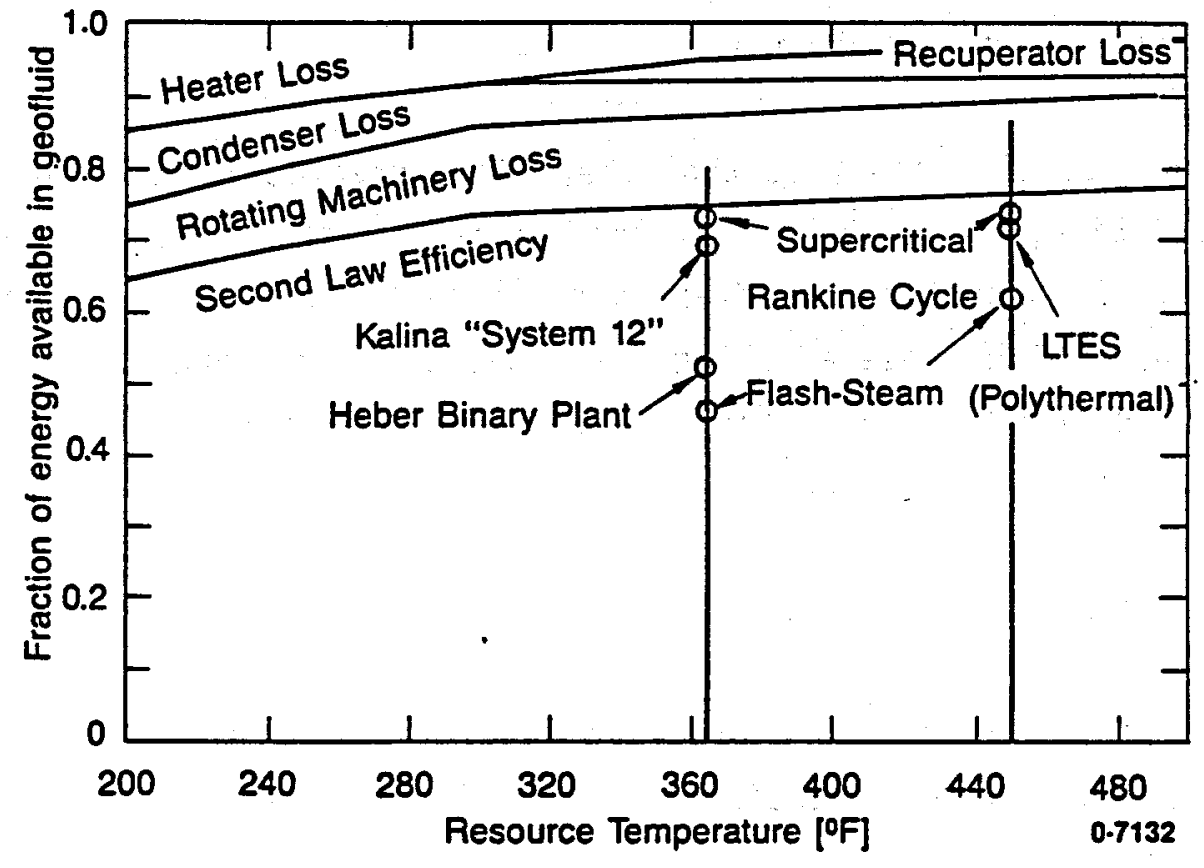

Figure 17. Results for advanced systems. 
Limits on geofluid outlet temperature (silica deposition limits) increase heat transfer irreversibilities; recuperation decreases these irreversibilities.

The different advanced systems considered here appear to be approaching this practical 1 imit and investigation for a particular application may favor one system over another. The design engineer must decide on the most cost-effective alternative based on all aspects of the systems.

This definition of practical limits does not include effects of heat source delivery systems or heat rejection systems. The geofluid supply and injection systems should be similar for all binary alternatives, however the heat rejection systems may be different because of the optimum cooling water temperature rise (or air temperature rise for dry cooling). These effects must be addressed separately. Obviousiy, the higher the geofluid effectiveness, the smaller the field necessary to support the plant and the less heat rejected, the smaller the heat rejection system will be to support the plant. 


\section{REFERENCES}

1. Demuth, 0.J., and Whitbeck, J.F., Advanced Concept Value Analysis for Geothermal Power P1ants, EGG-GTH-5821, March 1982.

2. Cassel, T. et al., Geothermal Well Field and power Plant Investment Decision Analysis, DOE-ET-27242-T1, May 31, 1981.

3. Demuth, 0.J., "Analysis of Binary Thermodynamic Cycles for a Moderately Low-Temperature Geothermal Resource," Proceedings of the 15th IECEC, American Institute of Aeronautics and Astronautics, Vol. 1, pp. 798-803, 1980.

4. Demuth, 0.J., "Analysis of Mixed Hydrocarbon Binary Thermodynamic Cycles for Moderate Temperature Geothermal Resources," Proceedings of the 16th IECEC, American Society of Mechanical Engineers, Vol. 2, pp. 1316-1321, 1981 .

5. Demuth, 0.J. and Kochan, R.J., "Analysis of Mixed Hydrocarbon Binary Thermodynamic Cycles for Moderate Temperature Geothermal Resources Using Regenerative Techniques, " Proceedings of 17th IECEC, Institute of Electrical and Electronics Engineers, Vol. 2, pp. 1104-1109, 1982.

6. Bliem, C.J., "Zeotropic Mixtures of Halocarbons as Working Fluids in Binary Geothermal Power Generation Cycles," Proceedings of the 22nd IECEC, American Institute of Aeronautics and Astronautics, Vo1. 2, pp. 930-935, 1987.

7. Demuth, 0.J., Bliem, C. J., Mines, G.L. and Swank, W.D., Supercritical Binary Geothermal Cycle Experiments with Mixed-Hydrocarbon Working Fluids and a Vertical. In-Tube, Counterflow Condenser, EGG-EP-7076, Idaho National Engineering Laboratory, December 1985.

8. Bliem, C. J., and Mines, G. L., "Relative Performance of Supercritical Binary Power Cycles With In-Tube Condensers in Different Orientations," Proceedings of the 24th IECEC, Institute of Electrical and Electronic Engineers, Vo1. 5, pp. 2167-2172, 1989. 
9. Kalina, A. I. and Leibowitz, H. M., "Application of the Kalina Cycle Technology to Geothermal Power Generation," Iransactions of the Geothermal Resources Council, Vol. 13, pp. 553-559, 1989.

10. Saulson, S. H. and Rosenblatt, J. H., "Analysis of Working Fluid Choices for Novel Cycle Applicable to Geothermal and Conventional Power Plants: An Interim Report, " Proceedings of 24th IECEC, Institute of Electrical and Electronics Engineers, Vol. 6, pp. 2789-2794, 1989.

11. Reference no. ETSU G 141, Hot Dry Rock Trilateral Wet Vapour Cycle Study, Project No. 4022-001, Energy Technology Support Unit, Department of Energy, U. $K$.

12. Obert, E. F., Concepts of Thermodynamics, McGraw-Hill Book Company, Inc., New York, 1960, Chapter 15.

13. Kalina, A. I., "Combined-Cycle System with Novel Bottoming Cycle," Journal for Engineering for Gas Turbines and Power, Vol. 106, pp. 737-742, 1984.

14. Bliem, C. J., "Simple Strategies for Minimization of Cooling Water Usage in Binary Power Plants," Transactions of the Geothermal Resources Council, Vo1. 13, pp. 553-559, 1989.

15. Fyfe, W.S., Price, N.J., and Thompson, A.B., Fluids in the Earth's Crust, Elsevier Scientific Publishing Company, Amsterdam-Oxford-New York, 1978, p. 75.

16. Demuth, 0.J., "Prel iminary Assessment of Condensation Behavior for Hydrocarbon Vapor Expansions Which Cross the Saturation Line Near the Critical Point," Proceedings of the 18th IECEC, American Institute of Chemical Engineers, Vol. 1, pp. 325-330, 1983.

17. Bl lem, C. J., Aspects of the Kal ina Technology Applied to Geothermal Power Production, INEL Report No. EGG-EP-8708, September 1989. 
18. Elliott, D. G., Theory and Tests on Two-phase Turbines, JPL Publications 81105, DOE/ER-10614-1, March 1982. 